Article

\title{
Nanostructured Broadband Solar Absorber for Effective Photothermal Conversion and Electricity Generation
}

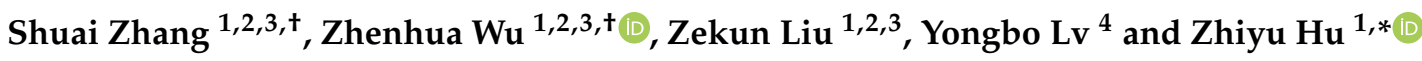 \\ 1 National Key Laboratory of Science and Technology on Micro/Nano Fabrication, Shanghai Jiao Tong \\ University, Shanghai 200240, China; zhangs0521@sjtu.edu.cn (S.Z.); wuzhenhua@sjtu.edu.cn (Z.W.); \\ liuzekun@sjtu.edu.cn (Z.L.) \\ 2 Department of Micro/Nano Electronics, School of Electronic Information and Electrical Engineering, \\ Shanghai Jiao Tong University, Shanghai 200240, China \\ 3 Institute of Nano/Micro Energy, Shanghai Jiao Tong University, Shanghai 200240, China \\ 4 School of Physics and Astronomy, Shanghai Jiao Tong University, Shanghai 200240, China; \\ lyb2676376@sjtu.edu.cn \\ * Correspondence: zhiyuhu@sjtu.edu.cn \\ + These authors contributed equally to this work.
}

Citation: Zhang, S.; Wu, Z.; Liu, Z.; Lv, Y.; Hu, Z. Nanostructured Broadband Solar Absorber for Effective Photothermal Conversion and Electricity Generation. Energies 2022, 15, 1354. https://doi.org/ $10.3390 /$ en15041354

Academic Editor: Vladislav

A. Sadykov

Received: 31 December 2021

Accepted: 11 February 2022

Published: 13 February 2022

Publisher's Note: MDPI stays neutral with regard to jurisdictional claims in published maps and institutional affiliations.

Copyright: (c) 2022 by the authors. Licensee MDPI, Basel, Switzerland. This article is an open access article distributed under the terms and conditions of the Creative Commons Attribution (CC BY) license (https:// creativecommons.org/licenses/by/ $4.0 /)$.

\begin{abstract}
Photothermal conversion is an environmentally friendly process that harvests energy from the sun and has been attracting growing research interest in recent years. However, nanostructured strategies to improve light capture performance deserve further development, and the application of solar heating effects for clean energy needs to be explored. Herein, a multiscale nanomaterial was prepared by in situ polymerizing the polyaniline (PANI) nanoparticles into porous anodic aluminum oxide (AAO) membrane. As a result, the as-prepared PANI-AAO shows broadband solar absorption and provides a platform for efficient photothermal conversion. What is more, we introduced a typical thermoelectricity generator (TEG) with excellent output performance and combined it with PANI-AAO to prepare a solar thermoelectric generator (s-TEG). The s-TEG harvests solar energy and converts it into electricity, showing an outstanding power generation capability in outdoor conditions. Thus, the nanostructured broadband solar absorber and the integrated solar thermoelectric generator offer a promising candidate for a sustainable and green energy source in the future.
\end{abstract}

Keywords: polyaniline nanoparticles; anodic aluminum oxide; solar absorber; thermoelectricity generator

\section{Introduction}

With industrial development and population growth, energy shortages and environmental degradation have become common issues all over the world [1]. Recently, mankind has gradually reduced its dependence on fossil fuels and developed renewable and clean energy [2,3]. Non-fossil energy such as wind energy, solar energy, hydro energy, biomass energy and geothermal energy is of great significance for protecting the ecological environment, coping with climate change and realizing sustainable economic and social development. For example, wind energy is the kinetic energy generated by air flow, which is renewable and widely distributed, and can be converted into heat energy and/or electric energy through comprehensive engineering technology. However, it has low energy density, instability and great technical difficulty. Hydro energy is mainly used for hydropower, which has the advantages of low cost, renewable and pollution-free, but it will be limited by natural conditions such as hydrology, the climate and landform. Therefore, there are still great challenges in the development of new green energy [1].

Since the birth of life on earth, it has mainly lived and multiplied with the thermal radiation energy provided by the sun. It is worth noting that most of the energy required by human beings comes directly or indirectly from the sun, including fossil energy, wind energy and hydropower. With the decrease in fossil fuels, solar energy has become an 
important part of human energy and has been developing continuously. Solar energy is inexhaustible green energy with properties of intrinsically abundant and global sustainability, and has been widely used in photovoltaic [4], photochemistry [5], photocatalysis [6,7], photothermal [8-10] and other fields. Using the photovoltaic effect, scientists have created photovoltaic cells to directly convert solar radiation into electrical energy. Photovoltaic cells have a wide range of applications, such as solar power plants and distributed roof photovoltaic [4]. Benefiting from technological progress, economies of scale and open market competition, photovoltaic power generation has developed rapidly in the past decade. However, due to the wavelength selectivity of the photovoltaic effect, photovoltaic cells can only use the visible part of solar radiation, which cannot be effectively used for the infrared region that accounts for most of the solar energy [8,9]. Therefore, among the various energy conversion pathways from solar illumination, solar-to-heat conversion is the most direct and efficient [11]. To take advantage of the free and green solar energy, studies investigating the mechanism, structural design and preparation methods of photothermal materials are urgently needed.

Generally speaking, photothermal conversion technology is a way that absorbs the electromagnetic energy in solar radiation and converts it into non-radiant heat to raise the temperature of the object [12]. An ideal photothermal material is a perfect blackbody that needs to completely absorb the incident sunlight with no reflection or transmission [13]. Towards the advanced photothermal conversion process, multiscale nanostructures are necessary to improve the absorption of incident sunlight with different wavelengths from all directions [14,15]. Multiscale micro/nano structures can form optical traps to trap photons in materials. Additionally, photons oscillate repeatedly between multiple interfaces and are gradually absorbed. Recently, significant efforts have been focused on multiscale nanophotonic materials, such as carbon nanotubes [16], graphene [17], MXene [18], semiconductor nanocrystals [19] and metal nanoparticles [20], due to their highly intriguing optical absorption and photothermal properties. Carbon-based materials often have large specific surface areas, unique electronic structures and optical properties. Efficient photothermal conversion can be realized through surface modification, skeleton structure design and assembly processing $[16,17]$. Metal materials have strong local surface plasmon resonance (LSPR) effects, adjustable sizes and morphologies, which make them typical representatives of solar absorbers [20]. However, there are several challenges associated with the design and fabrication of a nanostructured broadband solar absorber, such as reducing cost, regulating morphology and expanding production.

Organic materials with inherently conjugated structures have been gradually developed as emerging solar absorbers because of the lower manufacturing costs, better processability and broader chemical functionalization capabilities [21]. In addition, regulating the polymerization process and using templating agents could control the morphology of nanostructured polymers, such as nanofibers, nanospheres, nanoflowers, nanoribbons and nanotubes [22,23]. Recently, the optically active nanomaterials with degradable possibilities, such as polyaniline (PANI), polypyrrole (PPy) and polyaniline (PAN), have been prepared with different nanostructure morphologies and are widely used in biomedical application [24,25], solar-driven water evaporation [26], soft actuator [27] and solar energy storage [28]. Solar-driven water evaporation technology has attracted more and more attention because of its advantages of no consumption of conventional energy, no pollution and high purity of fresh water. The development of an efficient solar collector and desalination process is the key of solar-driven water evaporation technology. The nano-solar absorber can effectively realize the conversion of light-to-heat, and provides a channel for the transportation and removal of salt ions, which is an ideal platform for water evaporation and seawater desalination [26]. Although considerable efforts have been developed to realize nanostructured broadband solar absorbers, the direct conversion of solar energy into usable electric energy still requires additional efforts for practical and industrial applications.

Herein, we apply the nanostructured strategy to polymerize PANI nanoparticles in the AAO pores to improve the ability of light trap and photothermal conversion. The 
as-prepared solar absorber shows excellent broadband absorption across the full solar spectrum, especially in the ultraviolet-visible region with an absorptivity of more than $95 \%$. When irradiated by sunlight, the temperature of PANI-AAO can increase from 28 to $62{ }^{\circ} \mathrm{C}$ within $300 \mathrm{~s}$, showing the potential for effective solar heating. In addition, we combined the solar absorber with a typical thermoelectricity generator (TEG) to prepare a solar thermoelectric generator (s-TEG), which harvests energy from the sun and converts it directly into usable electric energy. In a word, the nanostructured broadband solar absorber and the integrated solar thermoelectric generator have the competitive potential for practical large-scale solar energy harvesting and power generation.

\section{Materials and Methods}

\subsection{Materials}

Aniline, Ammonium persulfate, Phytic acid ( $50 \%$ ) were provided by Aladdin Chemistry Co., Ltd., Shanghai, China. Anodic aluminum oxide (AAO) with a honeycomb-like structure was purchased from Shenzhen Topmembranes Technology Co., Ltd., Shenzhen, China. All reagents were of analytical grade and used directly without any purification.

\subsection{Measurements}

Scanning electron microscopy (SEM) images were taken with a Zeiss ULTRA55. Optical performance was measured by Ultraviolet-visible-NIR (UV-vis-NIR) absorption spectroscopy (Lamda 950, PerkinElmer Inc, Massachusetts, USA.). Thermal gravimetric analysis (TGA) was characterized by a thermogravimetric analyzer (TGA 8000, PerkinElmer Inc, Massachusetts, USA.) under $\mathrm{N}_{2}$ atmosphere. Simulated solar irradiation was provided by a xenon lamp (PL-X300DF) equipped with an AM 1.5 filter. The temperature was monitored by K-type thermocouples (TT-K, Omega Engineering Inc, Shanghai, China.) connected to a digital data acquisition system (DAQ 6510, Tektronix Inc, Shanghai, China.).

\subsection{Preparation of the Solar Absorber}

Prepared $50 \mathrm{~mL}$ mixed solution of ethanol and water according to the volume ratio of 1:4, added $5 \mathrm{~mL}$ phytic acid solution, $0.48 \mathrm{~g}$ ammonium persulfate, and mixed evenly. Added clean AAO film to the above solution with the porous side facing up. After soaking in an ice bath for ten minutes, $2.5 \mathrm{~mL}$ aniline monomer was added and ultrasonically mixed for about $10 \mathrm{~s}$ to obtain a homogenous solution, and then sealed and placed in the refrigerator at $5{ }^{\circ} \mathrm{C}$ for $24 \mathrm{~h}$.

\subsection{Preparation of the Solar Thermoelectric Generator}

Cut the prepared solar absorber to a size of $4 \times 4 \mathrm{~cm}$, and connected its back to the surface of the clean thermoelectric generator (TEG) with thermal conductive adhesive, so that the porous side attached with polyaniline faces the sky.

\subsection{Outdoor Performance of the Solar Thermoelectric Generator}

A power generation device was built on the roof of an outdoor building in Shanghai $\left(31^{\circ} 1^{\prime} 50^{\prime \prime} \mathrm{N}, 121^{\circ} 26^{\prime} 26^{\prime \prime} \mathrm{E}\right)$ to demonstrate the practical application potential of the prepared solar thermoelectric generator. The power generation device was placed at a height of half a meter from the ground, and there was no additional windshield to simplify the installation. The solar absorber was exposed to sunlight as much as possible, and an aluminum radiator was connected to the bottom of the power generation device to enhance the effect of outdoor power generation.

\section{Results and Discussion}

Polyaniline (PANI) is an excellent photothermal polymer that is characterized by $\pi$-conjugated backbones of contiguous $\mathrm{sp}^{2}$-hybridized carbon atoms and has been widely used in solar-to-heat conversion due to its advantages of cheap and easy to obtain, simple synthesis, good environmental stability and excellent broadband absorption properties [29]. 
In this work, we proposed a simple route to load polyaniline (PANI) nanoparticles on the surface of a commercial porous anodic aluminum oxide (AAO) membrane to design a new solar absorber with wideband absorption and high photothermal conversion efficiency. Porous AAO has adjustable pore size, large specific surface area and reformability, which provides a reliable template for the growth of PANI nanoparticles. As shown in Figure 1a, by solution polymerization, a large number of PANI nanoparticles were grown on the surface of AAO and formed dense clusters. In this case, the mixture of ethanol and water is used to improve the wettability of the AAO surface and facilitate the in situ polymerization of PANI. Ammonium persulfate realizes the oxidative doping of PANI to improve the mobility of the charge carrier and broaden the absorption bandwidth. Phytic acid, as a small molecule hydrogen bond donor-acceptor, contributes to the formation of the nanostructured PANI [30-32]. As a result, aniline forms polyaniline through oxidative polymerization, and under the regulation of phytic acid, polyaniline gradually evolves and aggregates into nanoparticles to fill the surface of AAO. In addition, phytic acid can also form coordination bonds with alumina surface, thus providing a site for the anchoring of polyaniline nanoparticles [25].


Figure 1. The preparation and structure of the solar absorber. (a) Schematic illustration of the preparation of photothermal materials PANI on a porous substrate. The SEM images of (b) AAO and (c) PANI-AAO.

The as-prepared PANI-AAO consists of a secondary structure, with PANI nanoparticles filled on the 3D skeleton of the porous AAO membrane, which is important for light capture and photothermal conversion. The top-view SEM images of the AAO membrane as shown in Figure 1b. It is clear to observe that the pore size distribution of the original AAO membrane is relatively uniform, and the pore diameter is about $200 \mathrm{~nm}$. As a result, this suitable scale of the nanopores will facilitate the embedding of PANI nanoparticles. As shown in Figure 1c, the PANI nanoparticles with a diameter of $\sim 20 \mathrm{~nm}$ are successfully "planted" on the surface of the AAO membrane with random orientations, similar to "potted plants". Here, the AAO membrane as a container provides a carrier for the growth of PANI nanoparticles. PANI gradually polymerizes in the solution, similar to how plants germinate and grow in the soil, and oxidant and phytic acid are the best nutrients.

With the development of nanomaterials and nanotechnology, multiscale hybrid materials have been proposed for efficient solar energy absorption due to their multiscale electromagnetic wave reflection/absorption interface. PANI is well known as an optically active conjugated polymer, which shows strong absorption in the solar spectral range and 
excellent photothermal conversion efficiency. Alumina can enhance the overall photothermal conversion ability due to its plasma resonance effect. At the same time, porous AAO can provide a template for the growth of polyaniline nanoparticles to form a multilevel structure. In our work, the PANI-AAO with a multiscale structure was developed as a sunlight collector, which could reduce the reflection and transmission of the incident light and could improve the absorption of sunlight by repeated oscillation to extend the optical path. As a result, the "planted" PANI nanoparticles enhanced their ability to absorb incident solar irradiation, showing efficient photothermal conversion under solar irradiation (Figure 2a). In addition, the ordered porous AAO membrane is conducive to the uniform diffusion of heat and improves the stability of the solar heating effect of the solar absorber (PANI-AAO). As shown in Figure 2b, the original AAO membrane has a poor light absorption ability in the infrared radiation region (blue curve), because of its highly reflective surface and intrinsic wide bandgap. Remarkably, the AAO template-assisted solar absorber (PANI-AAO) (red curve) shows much higher optical absorption within the whole solar radiation spectrum from 300 2500 nm, and even almost saturated absorption in the visible range. The result indicates that the incident sunlight may be "trapped" by the compound material and absorbed completely. The excellent light-trapping capability may stem from the randomly distributed PANI nanoparticles in the AAO membrane and is one of the key factors for highly efficient solar-to-heat conversion.
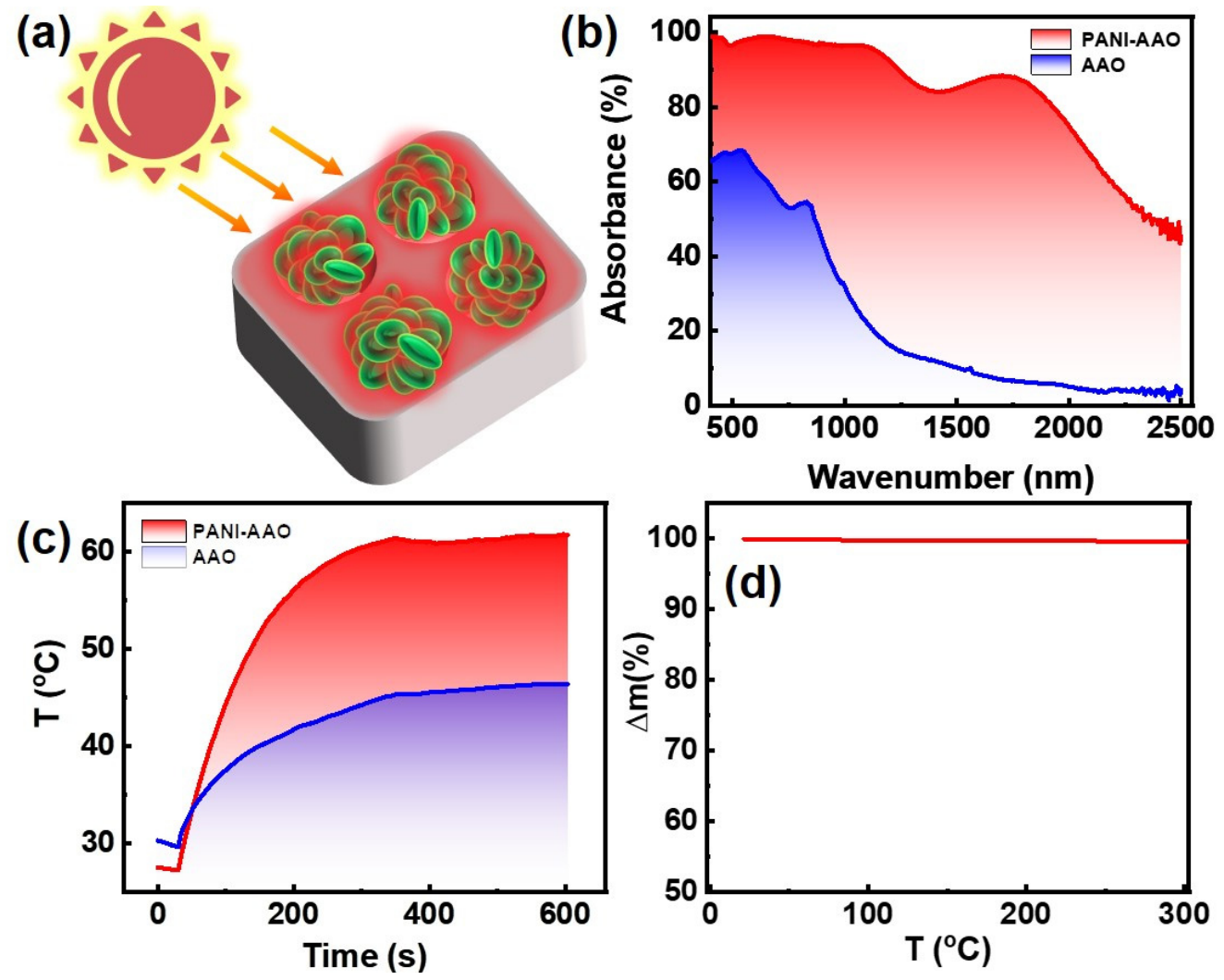

Figure 2. The photothermal conversion performance of the solar absorber. (a) The abridged schematic illustration of the solar heating effect. (b) The absorption spectrum of the AAO and AAO-PANI. (c) Time-dependent temperature variation of the AAO and PANI-AAO under one solar irradiation. (d) TGA curves of PANI-AAO.

To confirm the photothermal potential of PANI-AAO, the solar heating effect was measured under the solar radiation power of $1000 \mathrm{~W} / \mathrm{m}^{2}$ in ambient conditions. Obviously, under one sun illumination, the PANI-AAO shows a significant increase within $300 \mathrm{~s}$ and eventually heated up to an equilibrium temperature at $62{ }^{\circ} \mathrm{C}$, suggesting the excellent solar-to-heat conversion ability and short optical response time (Figure 2c). In contrast, 
the surface temperature of AAO could only reach $45^{\circ} \mathrm{C}$ from $30^{\circ} \mathrm{C}$. This improvement in the photothermal conversion performance promotes PANI-AAO to become a potential solar heating medium. However, the potential for practical application puts forward higher requirements for service life and environmental adaptability. Furthermore, the thermal stability of PANI-AAO is an important index to evaluate its potential applications under the complex environments in the future. As shown in Figure 2d, the thermogravimetric analysis (TGA) data of PANI-AAO show high thermal stability without weight loss from 25 to $300^{\circ} \mathrm{C}$ under a nitrogen atmosphere. This composite material with wide-spectrum absorption, efficient solar heating effect and thermal stability will provide an ideal candidate for the capture and utilization of solar energy. Furthermore, the solar absorber is composed of degradable polymers and biocompatible alumina, which is a potential environmentally friendly energy conversion system.

A thermoelectric generator (TEG) is a solid-state power device, which has the capability of directly converting thermal energy to electricity without any noise, vibration or gas emission [33,34]. A typical module of TEG mainly includes a $p$-type thermoelectric leg and an $n$-type thermoelectric leg connected electrically in series and thermally in parallel, in which the $p$-type has surplus holes and the $n$-type has surplus electrons to carry the electrical current. Based on the Seebeck effect, the temperature difference between the two sides of the TEG leads to the diffusion of the free charges (electrons or holes) along the heat flow driven by thermal excitation and generates an induced electrostatic potential (Figure 3a) [35,36]. At present, TEG is widely used in the fields of intelligent Internet of Things (IOT), wearable electronic devices, integrated power generation and waste heat recovery. With the development of new thermoelectric materials and the optimization design of power devices, TEG will gradually be applied to all aspects of industrial production and residents' life.
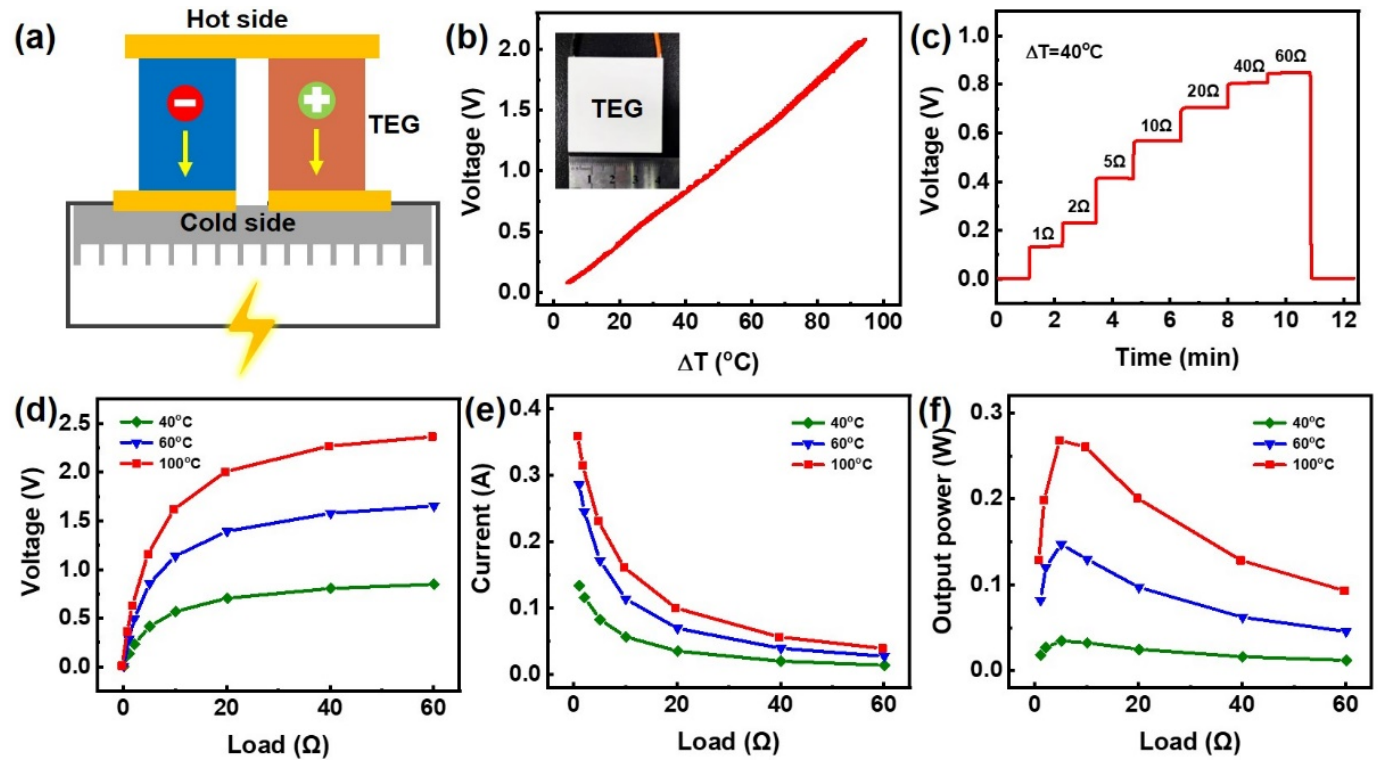

Figure 3. The output performance of TEG. (a) Schematic diagram of working principle of TEG. Output voltage of TEG as a function of temperature difference (b) and load (c). The output voltage (d), current (e) and power (f) of TEG under different temperature difference.

Herein, we chose a commercial TEG with a size of $4 \times 4 \mathrm{~cm}$ to understand its power generation capacity. As shown in Figure $3 b$, the open voltage values of TEG were measured as a function of the temperature difference. It is obvious that the open-circuit voltage increases as the temperature difference increases from 5 to $100{ }^{\circ} \mathrm{C}$ and shows a good linear relationship. Moreover, the generated voltage can reach up to a value of $2 \mathrm{~V}$, when the temperature difference is in the range of $100{ }^{\circ} \mathrm{C}$. To characterize the power generation capabilities of the TEG, the output voltage was acquired at various external load resistors 
from 1 to $60 \Omega$ at a fixed temperature difference of $40{ }^{\circ} \mathrm{C}$. This measurement is carried out by clamping the TEG between the hot plate and the cold plate. As shown in Figure $3 c$, the output voltage of TEG varies with the stepped load resistor and can reach $0.8 \mathrm{~V}$ at a load of $60 \Omega$.

We explore the relationship between output performance of the TEG and temperature difference and load resistance. It can be seen from Figure 3d,e that under the same temperature difference, with the increase of the external load resistor, the output voltage of TEG increases gradually, but the output current decreases gradually. Under the same load resistance condition, the increase of temperature difference results in the increase of output voltage and output current. When the load resistance is equal to the internal resistance of TEG, the output power of TEG is maximum. At the same time, as the temperature difference increases, the output power of TEG also increases, and we experimentally measured a high output power up to $0.27 \mathrm{~W}$ at a fixed temperature difference of $100{ }^{\circ} \mathrm{C}$ and a load resistance of $10 \Omega$ (Figure 3f).

Solar absorber (PANI-AAO) is the platform of solar-to-heat conversion, and TEG is the platform of thermo-to-electric conversion. The combination of the two parts will realize solar-to-electric conversion and put forward a reliable solution for the development of green and clean energy in the future. In this work, we adhered the homemade solar absorber (PANI-AAO) to the above TEG with a high thermal conductivity adhesive to prepare a solar thermoelectric generator (s-TEG), to develop the potential of the solar absorber in the field of green energy. As shown in Figure 2a, the PANI-AAO absorbs the sunlight and converts it into heat energy. At this time, the temperature difference between the upper and lower surfaces of the TEG can be established to drive the directional diffusion of carriers, thus generating voltage. If the strategy of optical concentration of solar radiation is implemented, the heat flux will increase and lead to a larger temperature difference in the actual environment. Figure $4 \mathrm{~b}$ shows the output performance of the s-TEG under different sun irradiation from $1,1.5$, and $2 \mathrm{~kW} / \mathrm{m}^{2}$. The steady-state output voltage increases with the increased solar intensity. Moreover, the s-TEG can achieve a high output voltage of $180 \mathrm{mV}, 230 \mathrm{mV}$, and $270 \mathrm{mV}$ at 1, 1.5, and 2 sun radiation, respectively, suggesting that high solar intensity leads to an increased output performance. We can see that if the effective solar radiation received on the surface of the solar absorber is improved through engineering and technical means, such as optical lens array to realize optical concentration, the comprehensive output performance of the generator will be greatly increased. The thermal stability of the solar absorber provides a reliable basis for this technical scheme (Figure $2 \mathrm{~d}$ ). What is more, the reversible voltage change against on-off light illumination under one sun irradiation shows the remarkable stability for a long working life.

In outdoor environments, solar irradiation is affected by geographical location, atmospheric and ground conditions. Here, we built the power generation device (s-TEG) on the roof of a building in Shanghai $\left(31^{\circ} 1^{\prime} 50^{\prime \prime} \mathrm{N}, 121^{\circ} 26^{\prime} 26^{\prime \prime} \mathrm{E}\right)$. The device is $0.5 \mathrm{~m}$ away from the ground, and there is no additional windshield in order to simplify the equipment. Then, we test the output performance of the s-TEG on a typically sunny and cloudy day and record the real-time solar irradiation intensity and output voltage. As shown in Figure 4c, the average solar intensity from 14:00 to $16: 00$ is $400 \mathrm{~W} / \mathrm{m}^{2}$. The output voltage of s-TEG changes in real time with the solar intensity and presents an average voltage output of $53 \mathrm{mV}$. However, on a typically clear day, the solar irradiation intensity decreases from 800 to $300 \mathrm{~W} / \mathrm{m}^{2}$ from 14:00 to 16:00. The s-TEG exhibits an average output voltage of $100 \mathrm{mV}$ and a peak voltage of nearly $150 \mathrm{mV}$ (Figure 4c). Changes in weather conditions and environmental factors, such as cloud movement, wind speed, humidity, etc., will have a significant impact on the effective solar radiation received by the solar absorber (PANI-AAO) and the conduction of heat at the interface and at both ends of the TEG. However, the change of output voltage signal also implies the sensitivity of the generator. In the future, with the optimization of equipment structure and the upgrading of power management system, the generator (s-TEG) will become a reliable and effective energy capture and power generation equipment in extreme environments and special fields. 
(a)

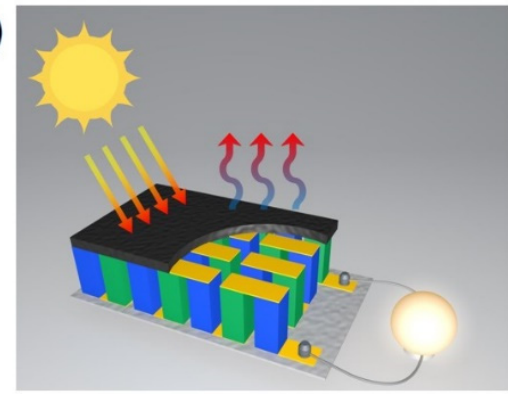

(b)





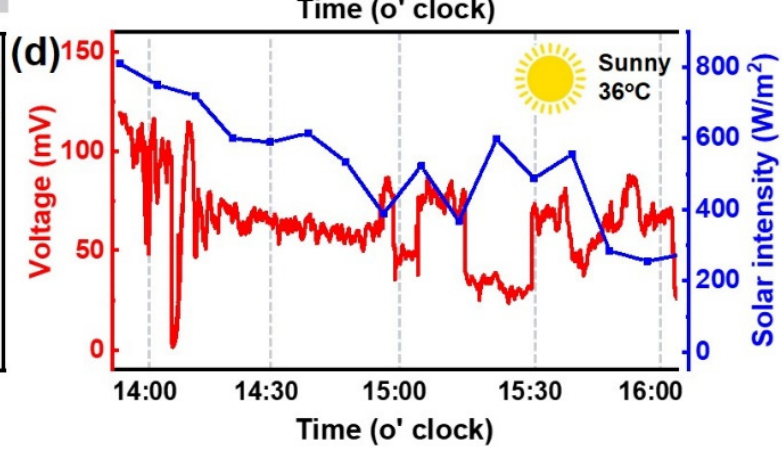

Figure 4. The output performance of the s-TEG. (a) Schematic illustration of s-TEG setup under sunlight. (b) The output performance of the s-TEG under different solar irradiation and the stability of on-off light illumination under one sun irradiation. The outdoor performance of the s-TEG in a typical (c) cloudy and (d) sunny day.

As shown in Figure $4 b$, the as-prepared s-TEG can achieve a high output voltage of $180 \mathrm{mV}$ under one sun irradiation. What is more, the output performance under one sun irradiation compared to the literature in Figure 5 shows the competitive performance and huge potential for power generation in this work. To sum up, an excellent s-TEG should have the following characteristics: 1 . Solar absorber with wide-spectrum absorption, which often needs to be designed from the perspective of material and structure; 2. TEG with high thermoelectric conversion efficiency, which requires the optimization of a thermoelectric system with high ZT value and device structure; 3 . High thermal conductivity and stable interface connection, because reducing interface thermal resistance will be conducive to the effective utilization of heat energy; 4 . The packaging of the generator can reduce the heat exchange between the solar heater and the environment, and improve the utilization of heat energy; and 5. Optical concentration and thermal concentration strategy. Improving the effective solar energy received by the solar absorber through the optical lens or optimizing the area ratio between the solar absorber and the TEG can further improve the power generation effect. These results and strategies indicate that the s-TEG will be more effective in low latitudes and high altitudes where solar radiation is more intense, and provide an alternative solution for alleviating power shortages in extreme environments.



Figure 5. The output voltage of the solar thermoelectric generator compared to the literature [37-42]. The detailed performance in this work is shown in Figure $4 \mathrm{~b}$. 


\section{Conclusions}

In this work, we prepared a multiscale nanostructured solar absorber (PANI-AAO) with PANI nanoparticles filled on the pores of AAO. The composite structure effectively harvests the solar energy and converts it into heat energy, notably with a surface temperature of up to $60{ }^{\circ} \mathrm{C}$ under one solar irradiation. In addition, we applied a commercial TEG to optimize the output performance by increasing the temperature difference and matching the external load. Finally, we combine the solar absorber and TEG to fabricate a solar thermoelectric generator (s-TEG), which shows a good power generation performance when tested outdoors. Through optical concentration, the s-TEG will have a wider application prospect. The demonstrated strong potential of the s-TEG opens up a path towards alleviating global climate problems and energy shortages.

Author Contributions: Conceptualization, S.Z., Z.W. and Z.H.; methodology, S.Z., Z.L. and Y.L.; investigation, S.Z., Z.L. and Z.W.; writing-original draft preparation, S.Z.; writing-review and editing, Z.W. and Z.H.; visualization, S.Z.; supervision, Z.H. All authors have read and agreed to the published version of the manuscript.

Funding: This research was funded by National Natural Science Foundation of China (51776126).

Institutional Review Board Statement: Not applicable.

Informed Consent Statement: Not applicable.

Data Availability Statement: The data that support the findings of this study are available from the corresponding author upon request.

Acknowledgments: This work was funded by the National Natural Science Foundation of China (grant no.: 51776126). We also thank the characterizations supported by the Instrumental Analysis Center of Shanghai Jiao Tong University and Center of Advanced Electronic Materials and Devices (AEMD).

Conflicts of Interest: The authors declare no conflict of interest.

\section{References}

1. Stancin, H.; Mikulcic, H.; Wang, X.; Duic, N. A Review on Alternative Fuels in Future Energy System. Renew. Sust. Energ. Rev. 2020, 128, 109927. [CrossRef]

2. Wang, H.; Xu, L.; Wang, Z. Advances of High-Performance Triboelectric Nanogenerators for Blue Energy Harvesting. Nanoenergy Adv. 2021, 1, 32-57. [CrossRef]

3. Wang, Y.; Duan, C.; Lv, P.; Ku, Z.; Lu, J.; Huang, F.; Cheng, Y.-B. Printing Strategies for Scaling-up Perovskite Solar Cells. Natl. Sci. Rev. 2021, 8, nwab075. [CrossRef]

4. Zhu, C.; Meng, L.; Zhang, J.; Qin, S.; Lai, W.; Qiu, B.; Yuan, J.; Wan, Y.; Huang, W.; Li, Y. A Quinoxaline-Based D-A Copolymer Donor Achieving 17.62\% Efficiency of Organic Solar Cells. Adv. Mater. 2021, 33, 2100474. [CrossRef]

5. Wang, Z.; Erhart, P.; Li, T.; Zhang, Z.-Y.; Sampedro, D.; Hu, Z.; Wegner, H.A.; Brummel, O.; Libuda, J.; Nielsen, M.B.; et al. Storing Energy with Molecular Photoisomers. Joule 2021, 5, 3116-3136. [CrossRef]

6. Wu, Z.; Lu, W.; Liang, X.; Dun, C.; Yan, S.; Mu, E.; Liu, Y.; Hu, Z. Formation of Hexagonal PdSe 2 for Electronics and Catalysis. J. Phys. Chem. C 2020, 124, 10935-10940. [CrossRef]

7. Wang, Z.; Li, C.; Domen, K. Recent Developments in Heterogeneous Photocatalysts for Solar-Driven Overall Water Splitting. Chem. Soc. Rev. 2019, 48, 2109-2125. [CrossRef]

8. Kim, J.U.; Lee, S.; Kang, S.J.; Kim, T. Materials and Design of Nanostructured Broadband Light Absorbers for Advanced Light-to-Heat Conversion. Nanoscale 2018, 10, 21555. [CrossRef]

9. Hong, J.; Xu, C.; Deng, B.; Gao, Y.; Zhu, X.; Zhang, X.; Zhang, Y. Photothermal Chemistry Based on Solar Energy: From Synergistic Effects to Practical Applications. Adv. Sci. 2021, 9, 2103926. [CrossRef]

10. Hasan, M.A.M.; Wang, Y.H.; Bowen, C.R.; Yang, Y. 2D Nanomaterials for Effective Energy Scavenging. Nano-Micro Lett. 2021, 13, 82. [CrossRef]

11. Wu, X.; Chen, G.; Owens, G.; Chu, D.; Xu, H. Photothermal Materials: A key Platform Enabling Highly Efficient Water Evaporation Driven by Solar Energy. Mater. Today Energy 2019, 12, 277-296. [CrossRef]

12. Cui, K.; Wardle, B.L. Breakdown of Native Oxide Enables Multifunctional, Free-Form Carbon Nanotube-Metal Hierarchical Architectures. ACS Appl. Mater. Interfaces 2019, 11, 35212-35220. [CrossRef] [PubMed]

13. Mizuno, K.; Ishii, J.; Kishida, H.; Hayamizu, Y.; Yasuda, S.; Futaba, D.N.; Yumura, M.; Hata, K. A Black Body Absorber from Vertically Aligned Single-Walled Carbon Nanotubes. Proc. Natl. Acad. Sci. USA 2019, 106, 6044-6047. [CrossRef] [PubMed] 
14. Ren, H.; Tang, M.; Guan, B.; Wang, K.; Yang, J.; Wang, F.; Wang, M.; Shan, J.; Chen, Z.; Wei, D.; et al. Hierarchical Graphene Foam for Efficient Omnidirectional Solar-Thermal Energy Conversion. Adv. Mater. 2017, 29, 1702590. [CrossRef] [PubMed]

15. Wang, X.; Liu, Q.; Wu, S.; Xu, B.; Xu, H. Multilayer Polypyrrole Nanosheets with Self-Organized Surface Structures for Flexible and Efficient Solar-Thermal Energy Conversion. Adv. Mater. 2019, 31, 1807716. [CrossRef] [PubMed]

16. Kiani, F.; Sterl, F.; Tsoulos, T.V.; Weber, K.; Giessen, H.; Tagliabue, G. Ultra-Broadband and Omnidirectional Perfect Absorber Based on Copper Nanowire/Carbon Nanotube Hierarchical Structure. ACS Photonics 2020, 7, 366-374. [CrossRef]

17. Anguita, J.V.; Ahmad, M.; Haq, S.; Allam, J.; Silva, S.R.P. Ultra-Broadband Light Trapping using Nanotextured Decoupled Graphene Multilayers. Sci. Adv. 2016, 2, e1501238. [CrossRef]

18. Cheng, H.; Liu, Q.; Han, S.; Zhang, S.; Ouyang, X.; Wang, X.; Duan, Z.; Wei, H.; Zhang, X.; Ma, N.; et al. Highly Efficient Photothermal Conversion of $\mathrm{Ti}_{3} \mathrm{C}_{2} \mathrm{~T}_{\mathrm{x}}$ /Ionic Liquid Gel Pen Ink for Smoothly Writing Ultrasensitive, Wide-Range Detecting, and Flexible Thermal Sensors. ACS Appl. Mater. Interfaces 2020, 12, 37637-37646. [CrossRef]

19. Hessel, C.M.; Pattani, V.P.; Rasch, M.; Panthani, M.G.; Koo, B.; Tunnell, J.W.; Korgel, B.A. Copper Selenide Nanocrystals for Photothermal Therapy. Nano Lett. 2011, 11, 2560-2566. [CrossRef]

20. Ma, C.; Yan, J.; Huang, Y.; Wang, C.; Yang, G. The Optical Duality of Tellurium Nanoparticles for Broadband Solar Energy Harvesting and Efficient Photothermal Conversion. Sci. Adv. 2018, 4, eaas9894. [CrossRef]

21. Namsheer, K.; Rout, C.S. Conducting Polymers: A Comprehensive Review on Recent Advances in Synthesis, Properties and Applications. RSC Adv. 2021, 11, 5659-5697.

22. Chao, D.; Zhu, C.; Yang, P.; Xia, X.; Liu, J.; Fan, X.; Savilov, S.V.; Lin, J.; Fan, H.J.; Shen, Z.X. Array of Nanosheets Render Ultrafast and High-Capacity Na-ion Storage by Tunable Pseudocapacitance. Nat. Commun. 2016, 7, 12122. [CrossRef] [PubMed]

23. Zhao, Y.; Arowo, M.; Wu, W.; Chen, J. Effect of Additives on the Properties of Polyaniline Nanofibers Prepared by High Gravity Chemical Oxidative Polymerization. Langmuir 2015, 31, 5155-5163. [CrossRef] [PubMed]

24. Ma, H.; Xue, M. Recent Advances in the Photothermal Applications of Two-Dimensional Nanomaterials: Photothermal Therapy and Beyond. J. Mater. Chem. A 2021, 9, 17569-17591. [CrossRef]

25. Zhang, S.; Xu, B.; Lu, X.; Wang, L.; Li, Y.; Ma, N.; Wei, H.; Zhang, X.; Wang, G. Readily Producing a Silly Putty-like Hydrogel with Good Self-Healing, Conductive and Photothermal Conversion Properties Based on Dynamic Coordinate Bonds and Hydrogen Bonds. J. Mater. Chem. C 2020, 8, 6763-6770. [CrossRef]

26. Zhao, F.; Zhou, X.; Shi, Y.; Qian, X.; Alexander, M.; Zhao, X.; Mendez, S.; Yang, R.; Qu, L.; Yu, G. Highly Efficient Solar Vapour Generation via Hierarchically Nanostructured Gels. Nat. Nanotechnol. 2018, 13, 489-495. [CrossRef]

27. Xuan, H.; Guan, Q.; Zhang, L.; You, Z. Thermoplastic Photoheating Polymer Enables 3D-Printed Self-Healing Light-Propelled Smart Devices. Adv. Funct. Mater. 2021, 31, 2009568. [CrossRef]

28. Wang, Z.; Roffey, A.; Losantos, R.; Lennartson, A.; Jevric, M.; Petersen, A.U.; Quant, M.; Dreos, A.; Wen, X.; Sampedro, D.; et al Macroscopic Heat Release in a Molecular Solar Thermal Energy Storage System. Energy Environ. Sci. 2019, 12, 187-193. [CrossRef]

29. Zare, E.N.; Makvandi, P.; Ashtari, B.; Rossi, F.; Motahari, A.; Perale, G. Progress in Conductive Polyaniline-Based Nanocomposites for Biomedical Applications: A Review. J. Med. Chem. 2020, 63, 1-22. [CrossRef]

30. Zhang, S.; Zhang, Y.; Li, B.; Zhang, P.; Kan, L.; Wang, G.; Wei, H.; Zhang, X.; Ma, N. One-Step Preparation of a Highly Stretchable, Conductive, and Transparent Poly(vinyl alcohol)-Phytic Acid Hydrogel for Casual Writing Circuits. ACS Appl. Mater. Interfaces 2019, 11, 32441-32448. [CrossRef]

31. Zhang, S.; Li, Y.; Zhang, H.; Wang, G.; Wei, H.; Zhang, X.; Ma, N. Bioinspired Conductive Hydrogel with Ultrahigh Toughness and Stable Antiswelling Properties for Articular Cartilage Replacement. ACS Mater. Lett. 2021, 3, 807-814. [CrossRef]

32. Pan, L.; Yu, G.; Zhai, D.; Lee, H.R.; Zhao, W.; Liu, N.; Wang, H.; Tee, B.C.-K.; Shi, Y.; Cui, Y.; et al. Hierarchical Nanostructured Conducting Polymer Hydrogel with High Electrochemical Activity. Proc. Natl. Acad. Sci. USA 2012, 109, 9287-9292. [CrossRef] [PubMed]

33. Wu, Z.; Zhang, S.; Liu, Z.; Mu, E.; Hu, Z. Thermoelectric Converter: Strategies from Materials to Device Application. Nano Energy 2022, 91, 106692. [CrossRef]

34. Jia, H.; Tao, X.; Wang, Y. Flexible and Self-Healing Thermoelectric Converters Based on Thermosensitive Liquids at Low Temperature Gradient. Adv. Electron. Mater. 2016, 2, 1600136. [CrossRef]

35. Mu, E.; Yang, G.; Fu, X.; Wang, F.; Hu, Z. Fabrication and Characterization of Ultrathin Thermoelectric Device for Energy Conversion. J. Power Sources 2018, 394, 17-25. [CrossRef]

36. Massetti, M.; Jiao, F.; Ferguson, A.J.; Zhao, D.; Wijeratne, K.; Wurger, A.; Blackburn, J.L.; Crispin, X.; Fabiano, S. Unconventional Thermoelectric Materials for Energy Harvesting and Sensing Applications. Chem. Rev. 2021, 121, 12465-12547. [CrossRef] [PubMed]

37. Li, K.; Xu, L.; Li, Z.; Wang, Y.; Wang, J.; Qi, X.; Li, Q.; Wang, H. Enhanced thermoelectric performance and tunable polarity in 2D Cu2s-phenol superlattices composites for solar energy conversion. Nano Energy 2021, 84, 105902. [CrossRef]

38. Li, K.; Sun, X.; Wang, Y.; Wang, J.; Dai, X.; Li, G.; Wang, H. All-in-one single-piece flexible solar thermoelectric generator with scissored heat rectifying p-n modules. Nano Energy 2022, 93, 106789. [CrossRef]

39. Jung, Y.S.; Jeong, D.H.; Kang, S.B.; Kim, F.; Jeong, M.H.; Lee, K.-S.; Son, J.S.; Baik, J.M.; Kim, J.-S.; Choi, K.J. Wearable solar thermoelectric generator driven by unprecedentedly high temperature difference. Nano Energy 2017, 40, 663-672. [CrossRef]

40. Kraemer, D.; Poudel, B.; Feng, H.-P.; Caylor, C.; Yu, B.; Yan, X.; Ma, Y.; Wang, X.; Wang, D.; Muto, A.; et al. High-performance flat-panel solar thermoelectric generators with high thermal concentration. Nat. Energy 2011, 10, 532-538. [CrossRef] [PubMed] 
41. Cao, P.; Zhao, L.; Yang, Z.; Yuan, P.; Zhang, Y.; Li, Q. Carbon Nanotube Network-Based Solar-Thermal Water Evaporator and Thermoelectric Module for Electricity Generation. ACS Appl. Nano Mater. 2021, 4, 8906-8912. [CrossRef]

42. Kim, C.; Kim, K. Enhancement of solar thermoelectric power generation by optical and thermal management with highly transparent aerogel window. Sol. Energ. Mat. Sol. C 2021, 230, 111224. [CrossRef] 